\title{
Undesirable specialization in the construction of composite policy indicators: The Environmental Performance Index
}

\author{
Nicky Rogge
}
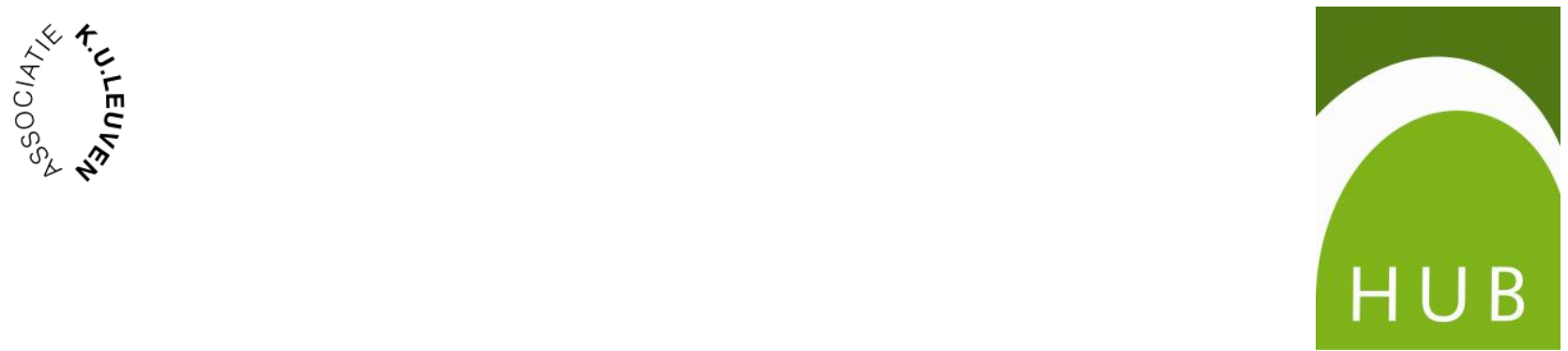


\title{
Undesirable specialization in the construction of composite policy indicators: The Environmental Performance Index
}

\author{
Nicky Rogge ${ }^{\diamond *}$ \\ (*): Hogeschool-Universiteit Brussel (HUBrussel) \\ Center for Business Management Research \\ Warmoesberg 26, 1000 Brussels (Belgium) \\ Tel.: +3226098834 \\ e-mail: Nicky.rogge@hubrussel.be \\ and \\ (\$): Katholieke Universiteit Leuven (KULeuven) \\ Faculty of Economics and Business \\ Naamsestraat 69, 3000 Leuven (Belgium) \\ Nicky.Rogge@econ.kuleuven.be
}

\begin{abstract}
The non-parametric Data Envelopment Analysis approach is increasingly used to construct composite indicators for country performance monitoring, benchmarking, and policy evaluation in a large variety of fields. The flexibility in the definition of aggregation weights is praised as the method's most important advantage: DEA allows each evaluated country to look for its own optimal weights that maximize the composite indicator relative to the other countries. However, this flexibility also carries a potential disadvantage as it may allow countries to appear as a brilliant performer in a manner that is hard to justify: by ignoring or overemphasizing one or multiple of the judiciously selected performance indicators. To illustrate this issue of undesirable specialization in DEA-based evaluations, this paper compares the Environmental Performance Index (EPI) as computed by the optimistic and pessimistic version of the DEA-model as proposed by Zhou et al. (2007). Based on both computed composites, undesirable specialization in performance is identified.
\end{abstract}

Keywords: Data envelopment analysis, benefit of the doubt, Composite indicators, Expert opinion, Undesirable specialization, Environmental Performance Index.

${ }^{\diamond}$ Corresponding author: Nicky.Rogge@HUBrussel.be, Nicky.Rogge@econ.kuleuven.be 


\section{Introduction}

Important international organizations such as the United Nations, the OECD, the World Economic Forum, and the European Commission increasingly call upon statisticians and academics to construct composite indicators (CIs) for purposes of public decision-making. Illustrative are the CIs which have recently been developed in wide ranging fields such as the economy (e.g., the Internal Market Index, the Competitiveness Index), the knowledge economy (e.g., the Knowledge Economy Indicator), human development (e.g., the Human Development Index), technological development (e.g., the Technology Achievement Index), health (e.g., the Health System Performance Index), and the environment (the Environmental Performance Index and the Environmental Vulnerability Index). ${ }^{1}$ The reason for this boost in the popularity of CIs is multifold. Next to the ability of summarizing key information on sometimes complex and elusive policy issues into a single index, CIs help decision makers by drawing attention to particular issues, identifying benchmark performances and trends, and setting policy priorities. In addition, they facilitate the task of ranking countries in terms of their overall performance on complex, multivariate tasks and/or policies. Furthermore, providing only the big picture, CIs often are easier to interpret by the media and the public. This makes them a real eye-catcher and, therefore, an attractive instrument for public communication.

Yet, for all their use, CIs continue to be the subject of controversy with antagonists claiming that their construction owes more to artisanship than to universally-accepted scientific rules for encoding. Most of the criticism is related to the question whether and how to weigh the individual performance indicators. Verifiable information regarding the true weights for the multiple indicators is usually lacking, which makes it not at all clear what weights to impute. In practice, typically, expert opinions are used to derive weights. However, as weighting information stemming from experts is often characterized by strong inter-individual disagreements, only resorting to experts does not solve the ambiguity issue completely.

In view of this vagueness, some researchers (e.g., Babbie, 1995; Hopkins, 1991) suggested equal weighting referring to the dictum that 'simple is better' (i.e., Occam's razor): "since it is probably impossible to obtain agreement on weights, the simplest arrangement [equal weighting] is the best choice" (Hopkins, 1991 p. 1471)2. However, this alleged simplicity is often thoroughly misleading. Occam's razor (the principle of parsimony) refers to choosing the simplest among 'otherwise equivalent models'. As argued by Cherchye et al. (2007), this prerequisite of

1 An extensive list of CIs can be found on the composite indicator information server (http://farmweb.jrc.cec.eu.int/ci/) provided by the Joint Research Centre of the European Commission. For an overview see also Singh et al. (2009)

${ }^{2}$ A quick glance at existing composite indicators reveals that a large majority of them are of the equal weighting type (e.g., Human Development Index, Technology Achievement Index, etc.). 
equivalence clearly does not hold in the construction of CIs because results (both CI-scores and CI-ranks) almost always depend on how underlying performance indicators are weighted. That is, the principle of parsimony provides no guidance in the search for proper weights and surely no justification for equal weighting. With this in mind, Cherchye et al. (2007) argued that the norm should be differential weighting. Fortunately, there is a weighting procedure in the literature that allows for differential weighting: the Benefit-of-the-Doubt (BoD) model (after Melyn and Moesen, 1991).

In essence, the BoD-model is particular version of the more popular Data Envelopment Analysis methodology, an efficiency measurement technique originally developed in the Operations Research and Management Science literature (Farrell, 1957; and Charnes, Cooper \& Rhodes, 1978). DEA has been widely praised for its ability to evaluate the efficiency performance of activity units (e.g., companies, production units, individuals, etc.), which operate in complex managerial and/or production contexts. The DEA-methodology and, hence, the related BoDmodel is non-parametric which implies that it does only assume minor a priori assumptions on the 'functional format' of the production frontier. Contrary to most other weighting approaches used in the construction of CIs (e.g., equal weighting (e.g., Skondras et al., 2011), Analytic Hierarchy Process (e.g., Singh et al., 2007), principal component analysis (e.g., Hosseini \& Kaneko, 2011), conjoint analysis, etc.), the BoD-model does not propose weights that are uniform over performance indicators and/or across evaluated countries. ${ }^{3}$ Instead, thanks to its linear programming approach, the BoD-model allows for an endogenous weighting of the underlying performance indicators. This data-driven weighting procedure is particularly effective in the construction of CIs where objective knowledge on the true weights is usually lacking. For each evaluated country separately, the BoD-model looks for the weights, which realize the highest possible CI-value. The intuitive reasoning is that, given the ambiguity and lack of consensus on the true weights, countries should have the freedom to use the weights in the built-up of the CI, which put them in the best possible light compared to the other countries. The advantage of this large freedom in the endogenous weighting is that it becomes hard for disappointed countries (i.e., countries with CI-values below expectations) to argue that the weights themselves put them at a disadvantage.

However, as this paper will argue, there is also an important potential shortcoming to this large freedom in BoD-based weighting. In some situations, it can allow countries to appear as brilliant performers in a way that is difficult to justify. To be more precise, in the basic BoD-model, there is nothing that keeps countries from assigning (quasi) zero weights and/or very high weights to one or more of the underlying performance indicators. This essentially allows countries to ignore some performance indicators while overemphasizing others. Obviously, in the attempt to maximise the own CI-value, each country will prefer ignoring (overemphasizing) the

\footnotetext{
${ }^{3}$ See Nardo et al., 2008 for a comprehensive overview.
} 
performance indicators on which it performs relatively poorly (strongly) compared to the other countries. Therefore, by allowing full freedom, one faces the risk of obtaining CIs that are only constructed based on a few of the (often meticulously) selected underlying performance indicators. In extreme evaluation scenarios, CIs may even only comprise the performance on one single performance indicator.

Practitioners using the BoD-model in the construction of CIs should be very aware of this possible shortcoming. Firstly, it may have a detrimental impact on the validity and reliability of CIs as measures of 'global' performance. Since the initial selection of performance indicators de facto embodies the commonly agreed objectives (typically by experts), each of the performance indicators is considered as somewhat pertinent to the multidimensional phenomenon under exploration. For that reason, it is hard to maintain that CIs based on only a small subset of the underlying performance indicators are adequate measures of the multidimensional phenomena they purport to quantify. Second, being an incentive-generating tool, poorly constructed (i.e., partial) CIs may generate inappropriate incentives for countries. In particular, when allowing full flexibility in BoD-based weighting, countries may be induced to put all effort into improving themselves on only one or a few of the selected performance criteria, while largely disregarding the performances on the others. Given the multidimensional characteristic of the evaluated phenomena, it is questionable whether such specialization is always an unqualified positive. Quite the contrary, very often, good 'global' performances on multidimensional phenomena require averagely good performances on all underlying criteria.

The above in mind, it seems risky to develop CIs using the BoD-model, this in spite of the several potential benefits offered by this construction methodology. Nevertheless, this paper argues that the BoD-model can provide credible CIs on the condition that this model is supplemented with additional weight restrictions. Preferably, these weight restrictions should be directly inspired by experts and/or stakeholders that have a wide spectrum of knowledge on the evaluated phenomenon to ensure that a proper weighting scheme is established.

The paper is organized as follows. The next section describes the BoD-version of the nonparametric Data Envelopment Analysis method to construct CIs. Following Zhou et al. (2007), this paper presents both the traditional, optimistic version and the pessimist variant of the BoDmodel. Both will play an essential role in the identification of (undesirable) specialization in performance. A section then follows which discusses the issue of undesirable specialization in BoD-based CIs. In particular, it is shown how the standard BoD-model allows countries to ignore (i.e., by assigning zero weights) or overemphasize (i.e., by selecting unrealistically high weights) one or more performance indicators. The issue of undesirable specialization is illustrated using data on the Environmental Performance Index 2010. The paper ends with a summary of the conclusion reached. 


\section{The 'Benefit-of-the-Doubt' (BoD) model}

\subsection{The (traditional) optimistic BoD-model}

The BoD-methodology to construct CIs is rooted in DEA, an efficiency measurement technique originally developed by Farrell (1957) and put into practice by Charnes et al. (1978) in the Operations Research literature. In essence, DEA is a non-parametric tool for evaluating the comparative efficiency of a set of similar activity units (e.g., companies, production units, individuals, countries, etc., referred to in the literature by Decision Making Units or DMUs) given data observations on (possibly multiple) used inputs and (possibly multiple) produced outputs and, often, no (exact) knowledge about the 'functional form' of the production or cost function. However broad, one immediately appreciates the conceptual similarity between the problem of measuring the efficiency of activity units in complex processes with no reliable information on prices and production functions, in the DEA-setting, and the one of constructing CIs based on an array of individual performance indicators that measure multi-dimensional concepts, and often no precise understanding on the true weights. In fact, in comparison to traditional DEA-setting, the only difference is that CIs only require a look at achievements (without explicitly taking into account the input dimension). ${ }^{4}$ Melyn and Moesen (1991) were the first to recognize this similarity. They alternatively labeled the DEA-methodology in the context of CI-construction as 'Benefit-of-the-Doubt' (BoD) approach, a label that originates from one of the remarkable features of the BoD-model (and, thus, the DEA-methodology): the use of an endogenous weight selection procedure in the aggregation of the multiple performance indicators. The conceptual starting point of the BoD-approach is that, in the absence of detailed knowledge on the correct weights for the underlying performance criteria, information on the weight can be retrieved from the observed performance data themselves (i.e., a posteriori letting the observed performance data speak by themselves). In particular, the basic idea of the BoD-model is to put each evaluated country in a relative perspective by comparing them to each other and looking for performance criteria of relative strength and relative weakness. The notion of 'benefit-of-the-doubt' enters into the specification of the weights. The BoD-model selects for each evaluated country the most favourable weights in a relative perspective to the performances of the other countries. As a result, each country obtains the highest possible CI-value. Formally, this point is covered by the max operator in the following linear programming problem (see also Cherchye et al., 2007):

\footnotetext{
${ }^{4}$ Formally, in the DEA setting, all evaluated units are assumed to have a 'dummy input' equal to one. The intuitive interpretation (see, amongst others, Melyn and Moesen, 1991 and Cherchye et al., 2007) for this focus may be obtained by simply looking upon this specific version of the DEA-model as a tool for summarizing performances on the several components of the evaluated phenomenon, without explicit reference to the inputs that are used for achieving such performances.
} 


$$
C I_{c}=\max _{w_{c, i}} \sum_{i=1}^{q} w_{c, i} y_{c, i}
$$

s.t.

$$
\begin{array}{ll}
\sum_{i=1}^{q} w_{c, i} y_{j, i} \leq 1 & j=1, \ldots, c, \ldots n \\
w_{c, i} \geq 0 & i=1, \ldots, q
\end{array}
$$

with $C I_{c}$ the optimal CI-value for the assessed country $c ; w_{c, i}$ the set of most favourable weights for country $c ; y_{j, i}$ the observed performances of all $n$ countries in the dataset $(j=1, \ldots, c, \ldots, n)$ on the $q$ underlying performance indicators (each measuring a particular aspect of the multidimensional phenomenon under scrutiny); and $y_{c, i}$ the measured performances of the evaluated country $c$ on the $q$ performance indicators. Assume without loss of generality that all $q$ performance indicators are 'goods' meaning that larger values indicate a better performance level.

In the basic BoD-model, only two minor constraints have to be satisfied: the normalization constraint $(1 a)$ and the non-negativity constraint $(1 b)$. The non-negativity constraint limits weights to be non-negative. The normalization constraint enforces that CIs for all countries in the dataset, computed with the optimal weights of the assessed country $c$, can at most be one (or, equivalently, $100 \%$ ). This means that for all countries, it holds that $0 \leq C I_{c} \leq 1$, with higher values indicating better overall performances. This normalization constraint also highlights the benchmarking idea of the BoD-model: the most favourable weights of each assessed country are always applied to the performances of all other countries. One is in that way, effectively looking for which of the other countries' performances are worse, similar or better. In this sense, BoDweighting may well entail that even when one grants the benefit-of-the-doubt to a country, it is still possible that its optimal CI-value is only a fraction of the CI-values obtained by other countries in the dataset (even if, optimal weights of the assessed country are highly probably less favourable than their own optimal BoD-weights). Hence, from the point of view of interpreting $C_{c}$, a value of one indicates that the evaluated country receives the highest possible CI being assessed optimally. One could say that this country acts as its own benchmark. On the other hand, a value below one reveals that there is at least one other country in the dataset which performs better that the evaluated country, even when applying optimal weights of the assessed country in the construction of the CI. From the point of view of improving the performance, the evaluated country is advised to focus on the countries that realized among the highest CI-values. The CIvalue then indicates the degree of superior performance. The closer $C I_{c}$ is to one, the closer is the evaluated country to its benchmark country. In other words, $C_{c}$-values that are considerably 
below one reveal that large improvements are required for the evaluated country to attain the same policy performance as the benchmark country.

The BoD-model as in $(1)-(1 b)$ nicely illustrates the underlying 'benefit-of-the-doubt' concept: in the absence of verifiable information on the true weights, the BoD-model allows each country to look for those weights, which put itself in the best possible light compared to the other countries. In particular, the basic idea is to allow each country to put its observed performances on the $q$ performance indicators in a relative perspective to the performances of the other countries, and look for the set of weights that maximize the impact of performance indicators of relative strength and minimize the influence of performance criteria of relative weakness. As a result, CIs estimated using the BoD-model as in $(1)-(1 b)$, are optimistic approximations of the true CIs. In other words, the traditional BoD-model implicitly assumes that optimal weighting (by means of a data-orientation in the weight definition) seems justifiable in a context of evaluating multidimensional performances in which there is usually uncertainty about, and lack of agreement among experts, on the true weights of the performance criteria. In that perspective, the classical application of the BoD-model can be seen as an 'optimistic' evaluation tool that grants countries the 'benefit of the doubt' in performance evaluations.

The advantage of the optimal, endogenous weighting in the traditional BoD-model is that it becomes hard for disappointed countries (i.e., countries with $C I_{c}$-values below expectations) to argue that the weights themselves put them at a disadvantage. However, as Zhou et al. (2007, p. 293) rightfully argued, there is also an important downside to this beneficial weighting. In particular, if a country is dominating all other countries in the sample set in terms of observed performances on a certain performance indicator, this country will always obtain a $C I_{c}$ equal to one (i.e., the highest possible score), irrespective of its performances on all other performance criteria. This essentially means that a country can be evaluated as an 'excellent performer' even if it performs very poorly on the majority of the underlying performance indicators. In addition, being an incentive-generating tool, poorly constructed (i.e., partial) CIs may generate inappropriate incentives for countries. In particular, when allowing full freedom in the BoDmodel, countries may be encouraged to put all effort into improving themselves on only one or a few of the selected performance aspects, while largely disregarding the performances on the other performance criteria. Given the multidimensional and complex nature of the evaluated phenomena, it is questionable whether such specialization is always an unqualified positive. ${ }^{5}$ Furthermore, full flexibility in beneficial weighting can allow countries to assign weights that contradict prior expert views on weights. To be more precise, countries can assign high (low) weights for performance indicators, which experts judge to be of secondary (primary) importance.

\footnotetext{
${ }^{5}$ Among others, Banker (1980) and Banker et al. (1989) conjectured that specialization in performance is a likely response to basic DEA-based (and, thus, BoD-based) evaluation tools.
} 
Finally, data-oriented, optimal weighting in the construction of CIs, may lead to evaluation scenarios where a large number of countries realize the maximum CI-value of one.

\subsection{The pessimistic version of the BoD-model}

With the above shortcomings of the large flexibility of the basic BoD-model in mind, Zhou et al. (2007) argued that it would also be interesting to look at how well countries perform vis-à-vis each other under the least favourable evaluation conditions. In particular, are countries able to keep up their good evaluation score relative to other countries under the 'worst-case' evaluation scenario? To answer this question, Zhou et al. (2007) developed the adverse, 'pessimistic' version of the BoD-model. This model is largely based on the minimum efficiency concept introduced by Zhu (2004) and applied by, among others, Takamura and Tone (2003) and Wang et al. (2007) in the DEA-context. The conceptual starting point of this pessimistic counterpart is opposite to the one of the traditional, 'optimistic' BoD-model. In particular, the pessimistic version looks, for each country separately, for the weights which evaluate this country in the worst possible way vis-à-vis the other countries. Formally,

$$
\begin{aligned}
& C I_{c}^{p}=\min _{w_{c, i}^{b}} \sum_{i=1}^{q} w_{c, i}^{p} y_{c, i} \quad \\
& \text { s.t. } \\
& \sum_{i=1}^{q} w_{c, i}^{p} y_{j, i} \geq 1 \quad j=1, \ldots, c, \ldots n \\
& w_{c, i}^{p} \geq 0 \quad i=1, \ldots, q
\end{aligned}
$$

With $C I_{c}^{p}$ the pessimistic value of the CI for the assessed country $c ; w_{c, i}^{p}$ the least favourable weights for this country $c$. Notice the large similarity between this 'pessimistic' version of the model and the traditional, 'optimistic' BoD-model. In fact, formally, both models differ only in the benchmark objective present in the optimization constraint ('min' vs. 'max') and the direction of the inequality sign in the normalization constraint (' $\geq$ ' vs. ' $\leq$ '). As a result of this opposite sign in the normalization constraint $(2 a)$, it holds that $1 \leq C I_{c}^{p}$ with higher values indicating better overall performances (in the sense that there are probably no or only few underlying performance indicators on which the evaluated country performs significantly weaker compared to the other countries). Values of $C_{c}^{p}$ close to one imply that there is at least one (and probably more) performance indicator(s) on which the evaluated country performs weaker compared to the majority of the other countries in the data set.

From point of view of intuition, however, the pessimistic weighting model differs significantly from its traditional, optimistic counterpart. As discussed previously, in the absence of exact 
knowledge on the true weights, the traditional BoD-model allowed each country to look for the most beneficial weights to evaluate them optimally relative to the other countries. The stance of pessimistic version of the BoD-model is the complete opposite. In particular, the pessimistic model enforces countries to assign high weights to performance indicators on which they perform relatively weakly and low weights on the criteria on which they perform relatively strongly. Or, to put it differently, in the construction of $C I_{c}^{p}$, the focus is on the criteria with the worst relative performances. In essence, the pessimistic variant of the weighting model evaluates how close each country is from the worst performing countries in the data set under the least favourable evaluation conditions (i.e., worst possible weights).

\section{3. (Undesirable) specialization in multidimensional performances}

In the aim of providing an overall evaluation of performances on multidimensional phenomena, the optimistic and pessimistic variants of the BoD-model approach the problem of ambiguity about the true weights from different angles. The suggestion of the traditional ('optimistic') BoDmodel is to put the focus on the underlying performance indicators on which the evaluated country is performing relatively strongly compared to the other countries. In so doing, the classical application of the BoD-model can be seen as an 'optimistic' evaluation tool that grants countries the 'benefit of the doubt' in performance evaluations. The pessimistic version of the BoD-model explores the opposite viewpoint because it looks at how well countries are performing when being evaluated using the least favourable, and, thus, most pessimistic weights (i.e., weights which put the emphasis on the performance indicators on which the assessed country performs relatively weak). By result, both models provide valuable 'performance bound' information. One the one hand, there is the optimistic $C I_{c}$, which indicates what is the best possible 'global' evaluation of a country's performance relative to the performances of the other countries. On the other hand, there is the pessimistic $C I_{c}^{p}$, which reflects the worst possible evaluation figure. As argued by Zhou et al. (2007), both scores mark out a range of CI-values (specific for each evaluated country) in which the exact $C I_{c}$ is believed to lie. However, these scores can provide also other interesting information. In particular, a brief comparison of the two 'boundary' CIs (and the rankings) can already provide an important indication of whether or not undesirable specialization is present in the performances of countries. As Figure 1 displays, the combination of $C I_{c}$ and $C I_{c}^{p}$ results in four possible scenarios.

\section{[Figure 1 about here]}

Countries with $C I_{c}$ and $C I_{c}^{p}$ near to one, typically have an overall performance that is characterized by large specialization (Quadrant I). More precisely, such countries not only have 
relatively good performances on some performance indicators but also relatively weak performances on other criteria. The few criteria with good relative performances enable countries to appear as good or even outstanding performers in the optimistic BoD-model. However, the underlying indicators with relatively poor performances prevent the same countries to realize good evaluations using the pessimistic version of the BoD-model. Countries which are evaluated as good or excellent performers under both the pessimistic and the optimistic versions of the BoD-model, usually perform very strongly on the majority (or all) of the underlying performance indicators relative to the other countries in the dataset (Quadrant II). Thus, there is relatively low specialization in the observed performances of such countries. A third evaluation scenario occurs when countries come out as poor relative performers irrespective of the version of the BoD-model used in the construction of the CIs (Quadrant III). In general, such countries perform relatively weakly on the majority or even all of the underlying performance criteria. This means that there is not one performance criterion on which these countries perform sufficiently strong enough compared to the other countries, to be evaluated as strong or outstanding performers using the most favourable weight in the CI-construction. Similar to the scenario depicted in Quadrant II, this implies rather uniform performances over all underlying performance indicators and, hence, no specialization in the performances. However, the evaluation scenario described here is much less optimistic in that performances on underlying indicators are situated at the lower end of the performance rankings. In the fourth and last evaluation scenario (quadrant IV), countries get both $C I_{c}$-values and $C I_{c}^{p}$-values significantly different from one (i.e., $C I_{c}<1$ and $C I_{c}^{p}>1$ ). Typically, such countries have moderate performance levels on the majority or all of the performance criteria. This leads to there being no performance criteria on which the countries perform strongly enough to appear as good or excellent performers in the optimistic BoD-model. On the other hand, such countries perform strongly enough on all performance indicators to avoid poor evaluations in the pessimistic weighting model. On average, specialization in country performance in this evaluation scenario is low to moderate.

By the classification described in Figure 1, high specialization only occurs when countries perform well under the most favourable evaluation conditions and weakly under the least favourable weighting conditions (i.e., Quadrant I). All the other combinations (Quandrants II, III and IV) point out low or moderate specialization in performance with rather homogeneous performance levels (respectively high, low, and low to moderate) on all or the majority of the underlying performance indicators. According to this reasoning, one could argue that undesirable specialization only arises when heterogeneity in country performance is such that it causes completely different CI-values and, thus, largely different rankings in the optimistic and pessimistic versions of the BoD-model. In the extreme case, a country receives twice the boundary CI-value of one. The $C I_{c}=1$ then indicates that the country is a brilliant performer whereas the $C I_{c}^{p}=1$ points to the complete opposite. Such a contradictory evaluation is possible 
for countries, which realize a very good or even the best performance on one of the underlying performance indicators while performing very poorly on another indicator (compared to the other assessed countries). Given the typically complex and multidimensional nature of the evaluated phenomena, an outstanding overall performance requires good to very good performances on all the underlying performance criteria.

\section{Restricting freedom in weight definition}

The observation that countries may easily inflate their CI-values by just ignoring one or more underlying performance indicators, without actually violating the basic restrictions, has often been constituted a weakness in the BoD-model (e.g. Chin et al., 2009 p. 249). Several authors (e.g. Cherchye et al., 2007, 2008; Wong and Beasley, 1990; and Roll et al., 1991) have therefore argued that the basic, full flexibility BoD-model may be too optimistic as it can lead to some countries being evaluated as outstanding performers in a way that is difficult to justify. Nevertheless, in spite of these warnings, several studies (e.g., Yoruk and Zaim, 2003; Zaim et al., 2003; Mahlberg and Obersteiner, 2001; and Storrie and Bjurek, 2000) computed CIs without limiting the freedom in weight choice. Roll et al. (1991) pointed out that it may be difficult to maintain that such CIs (especially if one or multiple underlying performance indicators receive zero weights after being meticulously selected by experts) really reflect the countries' performances with respect to the underlying performance indicators as a whole.

Fortunately, BoD-models are able to incorporate value judgments on what are appropriate weightvalues. This seems especially convenient in the case where individual expert opinion is available, but where experts disagree about the right set of weights. In such cases, the BoD-model is flexible to integrate some 'agreed judgments' by imposing weight restrictions. The result is then a restricted BoD-model in which countries can still choose their own weights optimally, but only within the a priori confines as agreed upon by the consulted experts (preferably people with a wide spectrum of knowledge about the studied phenomenon). Particularly with an eye towards practical applications, this approach of restricting flexibility in weight choice according to expert opinion is essential for the credibility and acceptance of CIs. The issue of imposing additional $a$ priori weight restrictions in the model has attracted considerable attention in the literature. This resulted in different types of weight restrictions (see Cherchye et al. (2007) and Thanassoulis et al. (2004) for a broad overview).

The advantages of incorporating prior expert views on weights in BoD-models are apparent. First, if experts agree that all selected performance indicators have some intrinsic importance in the evaluation of the studied phenomenon (which is very likely the case, since it is typically the same team of experts that initially agreed upon the selection of performance indicators), this agreement will be taken into consideration in the construction of the CI. More precisely, in the definition of 
the additional weight restrictions, lower bound values will be set equal to an appropriate minimum (e.g., the lowest weight assigned over all experts), higher than zero. This excludes unrealistic evaluation scenarios in which CIs only comprise a minority (or even just one) of the selected performance indicators. Further, by setting appropriate lower bound and upper bound values, experts can prevent undesirable specialization in the construction of CIs. In other words, experts can specify the bounds of additional weight restrictions such that only proper levels of specialization are possible in the built-up of CIs. This leads to another advantage of restricting BoD-models: it compels countries to choose optimal weights that are in correspondence with the a priori views of experts. This transforms the traditional BoD-model from an evaluation tool which was very likely too optimistic and, therefore, without sufficient discriminatory power, to an evaluation instrument which provides a balancing act between, on the one hand, unit-specific priorities and interpretations, and, on the other hand, general beliefs of what constitutes an excellent performance. Clearly, this benefits the credibility and legitimacy of CIs as evaluation tools. Evaluated countries will still be satisfied knowing that they can still choose their weights optimally. Experts will be more or less pleased with the fact that countries can only select weights, which satisfy the weight restrictions as agreed upon by themselves. Policy makers and decision makers also profit from CIs resulting from restricted BoD-models as the probability for misguiding signals decreases.

\section{Illustration}

In recent decades, there has been a growing awareness in society about the potential detrimental effects of the continued and unmanaged economic growth for the public health and welfare of current and future generations. This made the environmental performance of countries an established topic at the political agenda with politicians recognizing the pressing need for effective environmental policies. However, appropriate solutions are difficult to obtain (Jahn, 1998). One of the reasons for this difficulty in designing effective environmental policies is that environmental problems are highly complex to measure and to interpret. As a result, policymakers have to sort an enormous body of environmental data and, thereby, face complex challenges such as incomplete and conflicting data, causal complexity, varying values and preferences, and uncertainty (EPI 2010). To provide policy makers and other interested parties (e.g. environmental scientists, non-governmental organizations, the general public, etc.) with a quantitative basis for comparing, monitoring and evaluating the environmental policies of countries, several institutions (Yale University and Colombia University in joint work with the World Economic Forum and the Joint Research Centre of the European Commission) collaborated in the design of a composite indicator, the Environmental Performance Index (EPI), to benchmark the environmental performances of countries' policies. 
The Environmental Performance Index (EPI) ranks 163 countries on 25 performance indicators (selected by experts after an exhaustive analysis) ranked across ten core policy categories (with 1 to 4 indicators per category) covering both environmental public health and ecosystem vitality. Figure 2 displays the built-up of the EPI up to the ten core policy areas together with the weights used in the official version. For each policy area, a performance score is computed based on the performances realized by countries on the underlying performance indicators. Performance scores are then further weighted and aggregated to produce the EPI composite. In the original EPI, both the computation of the performance scores for the ten core policy areas and the aggregation of these scores into an overall EPI index are done by fixed weighting. The selection of the 25 underlying performance indicators, the grouping of these indicators in core policy areas, and the specification of the weights of indicators and policy areas, is the result of an extensive review of the scientific literature and consultations with experts in different domains.

[Figure 2 about here]

As an alternative to the traditional method of fixed weighting, in the remainder, the EPI is constructed using the optimistic and pessimistic versions of the BoD-model. In particular, the focus is on weighting and aggregation the scores on the ten core policy areas into the overall EPI. In the analysis, 43 countries are omitted due to missing data or zero values. This means that EPIs are constructed for the remaining 120 countries. As an illustration, the results are shown only for a subset of the countries in the EPI dataset. Table 1 lists the performance scores on the ten policy areas of EPI and the original composite EPI index for a sample of 8 countries (i.e., Finland, Brazil, Canada, Guinea, Costa Rica, Mexico, Indonesia, and UAE). This table also shows the ranking of the country per core policy area. This ranking already gives an indication of how good a country is performing relative to the other countries in the dataset in each core policy area. As discussed previously, this relative position will play an important role in the definition of a country's endogenous BoD-weights.

[Table 1 about here]

To illustrate the potential undesirable effect of granting countries too much freedom in the definition of the optimal, endogenous weights, EPI indices are first computed using the traditional, optimistic BoD-model without further restrictions on the weights. As argued above, this full flexibility version of the BoD-model suffers from the problem of allowing inappropriate weights (e.g. zero-weights). The resulting CIs as well as the absolute contributions (i.e., $w_{c, i} y_{c, i}$ ) of all ten core policy areas for the sample of 8 countries are listed in Table 2a. An analysis of these absolute contributions reveals that the majority of the 10 policy areas are ignored when using the optimistic BoD-model in the construction of the EPI. Finland, for instance, realizes the maximum EPI-score of one using only the policy area 'Air Quality for Human Health'. It should 
not be a surprise that this is the policy area in which Finland performs strongest compared to the other countries. ${ }^{6}$ A similar remark holds for the United Arab Emirates (UAE) that is also evaluated as an outstanding performer by only considering the policy area 'Forestry' in its EPI. Of the 8 countries listed in Table 2a, Brazil considers most (i.e., 6 out of 10) core policy areas in the construction of its EPI index.

On average, the EPI indices of the 120 countries in the analysis, resulting from the unrestricted optimistic BoD-model, comprise only 3.16 policy areas with, numbers ranging from 1 to 9 . Moreover, 87 of the 120 evaluated countries get the highest possible EPI-value equal to one. This would mean that, according to the basic BoD-based EPI-estimates, more than $2 / 3$ of the countries are excellent in terms of developing environmental policies. Intuitively, this result seems implausible. The computed EPI indexes are, therefore, to say the least, unrepresentative for the overall performances of the countries' environmental policies. Furthermore, in line with what has been discussed in previous sections, results clearly illustrate that the optimistic BoD-model enables undesirable specialization in the construction of CIs. In fact, being an incentivegenerating tool, the EPI constructed using the optimistic BoD-model, could motivate countries to put all effort into improving themselves on only one or a few of the core policy areas, while largely disregarding the performances on the others. Given the multidimensional characteristic of environmental problems, it is very much open to discussion whether such specialization is an unqualified positive. Rather the opposite seems to be true. To be effective, environmental policies require good performances on all (or at least a large majority of) the ten core policy areas.

[Table 2a about here]

[Table $2 \mathrm{~b}$ about here]

Following the reasoning of Zhou et al. (2007), EPI indexes are also computed using the pessimistic version of the BoD-model. The main question of interest is whether countries perform significantly differently relative to each other under the least favourable weighting conditions, compared to what the optimistic BoD-model indicated. The results for the 8 selected countries are displayed in Table $2 \mathrm{~b}$. In the interpretation of the resulting EPIs, recall that higher values indicate better overall performances. Several things can be noted from these results. First, the UAE is no longer evaluated as a brilliant performer. Instead, it receives the most pessimistic EPI-value of one which indicates that it realizes the worst overall environmental performance of all countries in the dataset when applying its least favourable weights to all countries. The UAE is a nice illustration of how the traditional, optimistic BoD-model may evaluate a country as an excellent

\footnotetext{
${ }^{6}$ Note that Finland realizes a strong relative performance on the policy area 'Forestry' as well. But as also 68 other countries also achieve the perfect performance of 100.00 in that area, it is less interesting for Finland to consider this policy area in its composite EPI index.
} 
performer by just considering one policy area in its EPI (i.e., undesirable specialization). In fact, a brief look at the performances and the rankings of the UAE on the ten policy areas (with the UAE appearing at the bottom of the ranking in 7 of the 10 policy areas!) already provides sufficient support to doubt the outstanding evaluation for the UAE resulting from the optimistic BoDmodel. Based on the above, the UAE is a nice example of a country belonging to the Quadrant I of highly (undesirably) specialized countries in Figure 1. With both $C I_{c}$ and $C I_{c}^{p}$ equal to one, Canada is another country that appears in this quadrant. Costa Rica, on the other hand, realizes the highest possible EPI-value of 1.6340 (of all 120 evaluated countries). This means that Costa Rica is the furthest away from the worst performing country when applying its own least favourable weights to all countries in the dataset. It is important to note that Costa Rica also is evaluated as an outstanding performer under the optimistic BoD-model (i.e., $C I_{c}=1$ ). Apparently, Costa Rica has performances on all ten core policy areas which enable this country to appear as a good performer using both the optimal and the worst possible weights in the construction of its composite EPI index. The performance scores and rankings realized by Costa Rica in the ten core policy areas of EPI, as displayed in Table 1, confirm this point largely. The combination of good optimistic and pessimistic EPIs leads to the positioning of Costa Rica in Quadrant II of Figure 1. Finland is another country that appears in this quadrant (with $C I_{c}=1$ and $\left.C I_{c}^{p}=1.3111\right)$. Guinea and Indonesia are two countries, which realize poor evaluation results under both the optimistic and pessimistic versions of the BoD-model (respectively $C I_{c}=0.8879$ and $C I_{c}=0.8840$ under the optimistic BoD-model and $C I_{c}^{p}=1$ when using the pessimistic version of the BoD-model). The performance scores listed in Table 1 indicate that these two countries perform 'average' or 'poor' in the majority of the EPI policy areas. By results, both countries belong to Quadrant III in Figure 1. Mexico and Brazil are examples of countries, which are evaluated as rather good performers using the optimal and the worst weights in the EPI construction (respectively with $C I_{c}=0.9121$ and $C I_{c}^{p}=1.2429$ for Mexico and $C I_{c}=0.9755$ and $C I_{c}^{p}=1.1442$ for Brazil). They appear in Quadrant IV of Figure 1. Overall, similar to what is observed when using the unrestricted optimistic BoD-model, the EPIs resulting from the full freedom, pessimistic version of the BoD-model, do not comprise all ten core policy areas (on average, the pessimistic BoD-based EPI comprises 5.8 policy areas). Thus, again, resulting partial EPIs are poor representations of countries' overall environmental performances.

The EPI-scores and ranks for the full sample of 120 countries as computed using the optimistic and pessimistic versions of the BoD-model are displayed in the upper part of Figure 3. Note in both these scatter plots the large number of countries with a composite EPI index of one under the optimistic evaluation conditions. Further note that of these countries with $C I_{c}=1$ there are several countries that perform poorly under the least favourable evaluation conditions (i.e., realizing $C I_{c}^{p}$ equal to one or in the neihgbourhood of one when being evaluated using the 
pessimistic version of the BoD-model). This clearly shows the point made earlier that using the basic BoD-model in the computations of the composite EPI-indices for countries may yield evaluation outcomes that are largely biased due to undesirable specialization in the construction of the EPI-indices. As discussed previously, such EPI-indices are to be avoided in the EPI-related policy evaluations of countries.

[Figure 3 about here]

To exclude unrealistic evaluations in which EPIs only comprise a minority or even just one of the ten core policy areas (and, hence, to prevent undesirable specialization in the construction of the EPI), additional weight restrictions are introduced in the optimistic BoD-model. As argued by Cherchye et al. (2007, 2008) and Zhou et al. (2007), proportional weight restrictions (alternatively labeled as proportion constraints) seem attractive from practical perspective of letting experts and/or stakeholders make a 'limited agreement' on the definition of the weights. Formally,

$$
\alpha_{i} \leq \frac{w_{c, i} y_{c, i}}{\sum_{i=1}^{q} w_{c, i} y_{c, i}} \leq \beta_{i}
$$

This restriction-type limits the relative weight of the core policy area $i$ in the composite EPI index to vary between an a priori defined lower bound $\alpha_{i}$ and upper bound $\beta_{i}$. Typically, evaluators will look for a balance between, on the one hand, freedom in the definition of optimal weights and, on the other hand, conformity to some general specifications on the appropriate values of these weights (as determined by experts/stakeholders). In the example of the EPI, one could allow each country some flexibility in choosing optimal weights around the weights used in the construction of the official EPI. For instance, the lower bound value $\alpha_{i}$ and the upper bound value $\beta_{i}$ could be set equal to this weight respectively minus $25 \%$ and plus $25 \%$. In the example of the core policy area 'Environmental Burden of Disease', this would yield $\alpha_{i}=0.25 \times 0.75=0.1875$ and $\beta_{i}=0.25 \times 1.25=0.3125$. The absolute and percentage contributions of the ten policy areas for the subset of 8 countries are displayed in Table $3 \mathrm{a}$ and $3 \mathrm{~b}$.

[Table 3a about here]

[Table $3 \mathrm{~b}$ about here]

Several things can be noted in Tables $3 \mathrm{a}$ and $3 \mathrm{~b}$. First, introducing additional restrictions in the BoD-model results in EPI-values that are equal or lower than those resulting from the 'full flexibility' optimistic BoD-model calculations. From a mathematical point of view, this is just 
what is to be expected: adding restrictions to an optimization problem will never increase the value of its objective function. Second, the absolute contributions of the policy areas sum up to the exact EPI-value. Third, BoD-obtained percentage contributions of policy areas can be quite diverse without violating the additional weight restrictions. Fourth, without pursuing in greater detail, note that it may be interesting to check whether and where imposed bounds are binding. Upwardly (downwardly) binding constraints imply that a country would probably have done better if these bounds had been relaxed (by assigning respectively higher (lower) optimal weights). Therefore, upwardly (downwardly) binding restrictions reveal policy areas of relative strength (weakness) in the composite EPI index (respectively indicated with the superscripts 'W' and ' $S$ ' in Table 3b). Finally, yet importantly, remark that all ten core policy areas are considered in the construction of the BoD-estimated EPI, with contributions varying around the weights used in the official EPI. This makes that the EPIs resulting from the optimistic, restricted BoD-model, provide a well-balanced picture of countries' overall environmental performances. This picture also shows in the Figure 3 (lower part) which displays the EPI-scores and ranks as computed using the restricted optimistic and restricted pessimistic versions of the BoD-model. In both scatter plots, EPI-scores and ranks are more related to each other compared to what is observed in the scatter plots of the unrestricted BoD-based evaluations.

\section{Conclusion}

CIs are increasingly used for policy, planning, and decision-making in complex and multidimensional situations. Yet, for all their use, CIs continue to be the subject of controversy. Most of the criticism is related to the question whether and how to weigh the multiple underlying performance criteria into an overall summarizing picture. Verifiable information regarding the true weights for the multiple indicators is usually lacking, which makes it not at all clear what weights to impute. In view of this ambiguity, this paper strongly argues in favour of differential weighting by proposing a specialized version of the well-know Data Envelopment Analysis methodology: the 'Benefit-of-the-Doubt' (BoD) model. The advantages of this methodology are multifold, several of which are discussed in this paper. Perhaps the most important methodological advantage of the BoD-model is that, unlike most traditional approaches, it does not advocate using weights that are uniform over underlying performance criteria and/or across evaluated countries. Instead, the BoD-model suggests for a flexible data-orientation in the weighting that enables countries to look for the own optimal weights so that they can evaluate themselves in the best possible light relative to the other countries. The intuitive reasoning is that, given the ambiguity and lack of consensus on the true weights, countries should have the freedom to use those weights, which result in the highest CI-value. 
However, as this paper argued, there is also an important potential shortcoming to this large freedom in weight choice in the basic, optimistic BoD-model. In some situations, it can allow countries to appear as brilliant performers in a way that is difficult to justify, by overemphasizing one or more underlying performance criteria while ignoring the others. Therefore, by allowing full freedom, one faces the risk of obtaining CIs, which are only constructed based on a few of the (often meticulously) selected underlying performance indicators. In extreme evaluation scenarios, CIs may even only comprise the performance on one single performance indicator. This paper warns practitioners who use the BoD-model in the construction of CIs for this potential shortcoming of full flexibility in the weight definition. Being an incentive-generating tool, poorly constructed (i.e., partial) CIs may encourage countries to put all effort into improving themselves on only one or a few of the selected performance criteria, while largely disregarding the performances on the others. Given the multidimensional characteristic of the evaluated phenomena, it is questionable whether such specialization is always an unqualified positive. Quite the contrary, very often, good 'global' performances on multidimensional phenomena require averagely good performances on all underlying criteria.

With these shortcomings of beneficial weighting in mind, Zhou et al. (2007) argued that it would also be interesting to look at how well countries perform vis-à-vis each other under the least favourable evaluation conditions. To do so, they developed the pessimistic version of the BoDmodel. By construction, the optimistic and pessimistic variants of the BoD-model approach the problem of ambiguity about the true weights from a different angle, thereby providing valuable 'performance bound' information. What is also interesting is that a comparison of the 'boundary' CIs can already provide an important indication of whether or not (undesirable) specialization is present in the performances of countries. Based on this comparison, this paper distinguishes between four possible evaluation scenarios: high (undesirable) specialization, low specialization (overall good), low specialization (overall poor), and low to moderate specialization (overall mediocre). Particularly the countries belonging to the group of high (undesirable) specialization pose a problem for practitioners basing themselves solely on the optimistic BoD-model in the CIconstruction. To be more precise, the traditional, optimistic BoD-model allows these countries to appear as outstanding performers just because of very good performances on one or a few of the underlying performance indicators. The fact that these countries also perform very weakly on one or more of the other performance criteria makes no difference in the optimistic BoD-model. Obviously, good 'global' performances on multidimensional phenomena require averagely good performances on all underlying performance criteria. Therefore, the optimistic BoD-model can lead to rather undesirable evaluation outcomes. This paper discusses one interesting way of overcoming this potential disadvantage of the traditional BoD-model: restricting the flexibility in the endogenous weighting by adding extra restrictions as specified by experts. The result is then a restricted, optimistic BoD-model, an evaluation tool which provides a balancing act between, on 
the one hand, country-specific priorities and interpretations, and, on the other hand, general beliefs of what constitutes an excellent performance.

\section{Acknowledgments}

The author wishes to express his gratitude to Prof. Dr. Tom Van Puyenbroeck, Prof. Dr. Laurens Cherchye, Prof. Dr. Wim Moesen, Prof. Dr. Erwin Ooghe, Prof. Dr. Bieke de Fraine, and Prof. Dr. Geraint Johnes for their constructive comments. 


\section{Literature}

Babbie, E. (1995). The Practice of Social Research. Wadsworth Publishing Company, Belmont.

Banker, R.D. (1980). A game theoretic approach to measuring efficiency. European Journal of Operational Research 5: 262-268.

Banker, R.D., Charnes, A., Cooper, W.W., \& Clarke, R. (1989). Constrained game formulations and interpretations for data envelopment analysis. European Journal of Operational Research 40: 299-308.

Charnes, A. Cooper, W.W., \& Rhodes, E. (1978). Measuring the efficiency of decision making units. European Journal of Operational Research 2: 429-444.

Cherchye L., Moesen, W., Rogge, N., \& Van Puyenbroeck, T. (2007). An introduction to 'benefit of the doubt' composite indicators. Social Indicators Research 82(1): 111-145.

Cherchye L., Moesen, W., Rogge, N., Van Puyenbroeck, T., Saisana, M., Saltelli, A., Liska, R., \& Tarantola, S. (2008). Creating composite indicators with DEA and robustness analysis: The case of the Technology Achievement Index. The Journal of the Operational Research Society 59(2): 239-251.

Chin, K. S., Wang, Y.M., Kwai Poon, G.K., \& Yang, J.B. (2009). Failure mode and effects analysis by data envelopment analysis. Decision Support Systems 48: 246-256.

Environmental Performance Index (EPI) 2010. Yale University, Colombia University, World Economic Forum, \& Joint Research Centre of the European Commission.

Farrell, M.J. (1957). The measurement of productive efficiency. Journal of the Royal Statistical Society, Series A, CXX Part 3: 253-290.

Hopkins, M. (1991). Human development revisited: A new UNDP report. World Development 19: 1496-1473.

Hosseini, M.H., \& Kaneko, S. (2011). Dynamic sustainability assessment of countries at the macro level: A principal component analysis. Ecological Indicators 11(3): 811-823.

Jahn, D. (1998). Environmental performance and policy regimes: Explaining variations in 18 OECD-countries. Policy Sciences 31(2): 107-131.

Mahlberg, B., \& Obersteiner, M. (2001). Remeasuring the HDI by data envelopment analysis. IIASA Interim Report IR-01-069, Luxemburg.

Melyn, W., \& Moesen, W. (1991). Towards a Synthetic Indicator of Macroeconomic Performance: Unequal Weighting when Limited Information is Available. Public Economics Research Paper 17, CES, KU Leuven. 
Nardo, M., Saisana, M., Saltelli, A., Tarantola, S., Hoffman, A., \& Giovannini, E. (2008). Handbook on constructing composite indicators: methodology and user guide. OECD and JRC (European Commision).

Available at: http://browse.oecdbookshop.org/oecd/pdfs/browseit/3008251E.PDF

Roll Y, Cook, W.D., \& Golany, B. (1991). Controlling factor weights in data envelopment analysis. IIE Trans 23: 2-9.

Singh, R.K., Murty, H.R., Gupta, S.K, \& Dikshit, A.K. (2007). Development of composite sustainability performance index for steel industry. Ecological Indicators 7(3): 565-588.

Singh, R.K., Murty, H.R., Gupta, S.K, \& Dikshit, A.K. (2009). An overview of sustainability assessment methodologies. Ecological Indicators 9(2): 189-212.

Skondras, N.A., Karavitis, C.A., Gkotsis, I.I, Scott, P.J.B., Kaly, U.L. \& Alexandis, S.G. (2011). Application and assessment of the Environmental Vulnerability Index in Greece. Ecological Indicators 11(6): 1699-1706.

Storrie, D., \& Bjurek, H. (2000). Benchmarking European Labour Market Performance with Efficiency Frontier Techniques. CELMS Discussion Paper. Göteborg University.

Takamura, Y., \& Tone, K. (2003). A comparative site evaluation study for relocating Japanese government agencies out of Tokyo. Socio-Economic Planning Sciences 37: 85-102.

Thanassoulis, E., Portela, M.C., \& R. Allen, R. (2004). Incorporating Value Judgements in DEA. in W. W. Cooper, L. Seiford and J. Zhu (eds.). Handbook on Data Envelopment Analysis. Kluwer Academic Publishers, Dordrecht: 99-138.

Wang, Y.M., Chin, K.S., \& Yang, J.B. (2007). Measuring the performances of decision-making units using geometric average efficiency. The Journal of the Operational Research Society 58: 929-937.

Wong, Y.-H. B., \& Beasley, J.E. (1990). Restricting Weight Flexibility in Data Envelopment Analysis. The Journal of the Operational Research Society 41(9): 829-835.

Yoruk, B.K., \& Zaim, O. (2003). Measuring the quality of life in European Union: The case of Turkey as a candidate state. International Journal of Social Economics 30(11): 1162-1176.

Zaim, O., Färe, R., \& Grosskopf, S. (2003). An economic approach to achievement and improvement indexes. Social Indicators Research 56(1): 91-118.

Zhou, P., Ang, B.W., \& Poh, K.L. (2007). A Mathematical Programming Approach to Constructing Composite Indicators. Ecological Economics 62: 291-297. 
Zhu, J. (2004). A buyer-seller game model for selection and negotiation of purchasing bids: extensions and new models. European Journal of Operational Research 154: 150-156. 
Figure 1: Evaluation scenarios

\begin{tabular}{|l|c|c|}
\hline & $C I_{c}^{p}(y)$ near 1 & $\begin{array}{l}C I_{c}^{p}(y) \text { significantly } \\
\text { greater than 1 }\end{array}$ \\
\hline$C I_{c}(y)$ near 1 & $\begin{array}{c}\text { High Specialization } \\
\text { (mixed) }\end{array}$ & $\begin{array}{c}\text { Low specialization } \\
\text { (overall good) }\end{array}$ \\
\hline $\begin{array}{l}C I_{c}(y) \text { significantly } \\
\text { lower than 1 }\end{array}$ & $\begin{array}{c}\text { Low specialization } \\
\text { (overall poor) }\end{array}$ & $\begin{array}{c}\text { Low to moderate } \\
\text { specialization } \\
\text { (overall mediocre) }\end{array}$ \\
\hline
\end{tabular}


Figure 2: Environmental Performance Index (EPI)

\begin{tabular}{|c|c|c|}
\hline \multirow{10}{*}{$\begin{array}{c}\text { Environmental Performance } \\
\text { Index (EPI) }\end{array}$} & \multirow{3}{*}{$\begin{array}{l}\text { Environmental Health } \\
\qquad(50 \%)\end{array}$} & $\begin{array}{c}\text { Environmental Burden of Disease } \\
(25 \%)\end{array}$ \\
\hline & & $\begin{array}{l}\text { Water Resources for Human Health } \\
\qquad(12.5 \%)\end{array}$ \\
\hline & & $\begin{array}{l}\text { Air Quality for Human Health } \\
\qquad(12.5 \%)\end{array}$ \\
\hline & \multirow{7}{*}{$\begin{array}{l}\text { Ecosystem Vitality } \\
\qquad(50 \%)\end{array}$} & $\begin{array}{l}\text { Air Quality for Ecosystems } \\
\qquad(4.2 \%)\end{array}$ \\
\hline & & $\begin{array}{l}\text { Water Resources for Ecosystems } \\
\qquad(4.2 \%)\end{array}$ \\
\hline & & Biodiversity and Habitat \\
\hline & & $\begin{array}{l}\text { Forestry } \\
(4.2 \%)\end{array}$ \\
\hline & & $\begin{array}{c}\text { Fisheries } \\
(4.2 \%)\end{array}$ \\
\hline & & $\begin{array}{c}\text { Agriculture } \\
(4.2 \%)\end{array}$ \\
\hline & & $\begin{array}{c}\text { Climate Change } \\
(25 \%)\end{array}$ \\
\hline
\end{tabular}


Figure 3: EPI-scores and ranks: unrestricted vs restricted BoD-based weighting
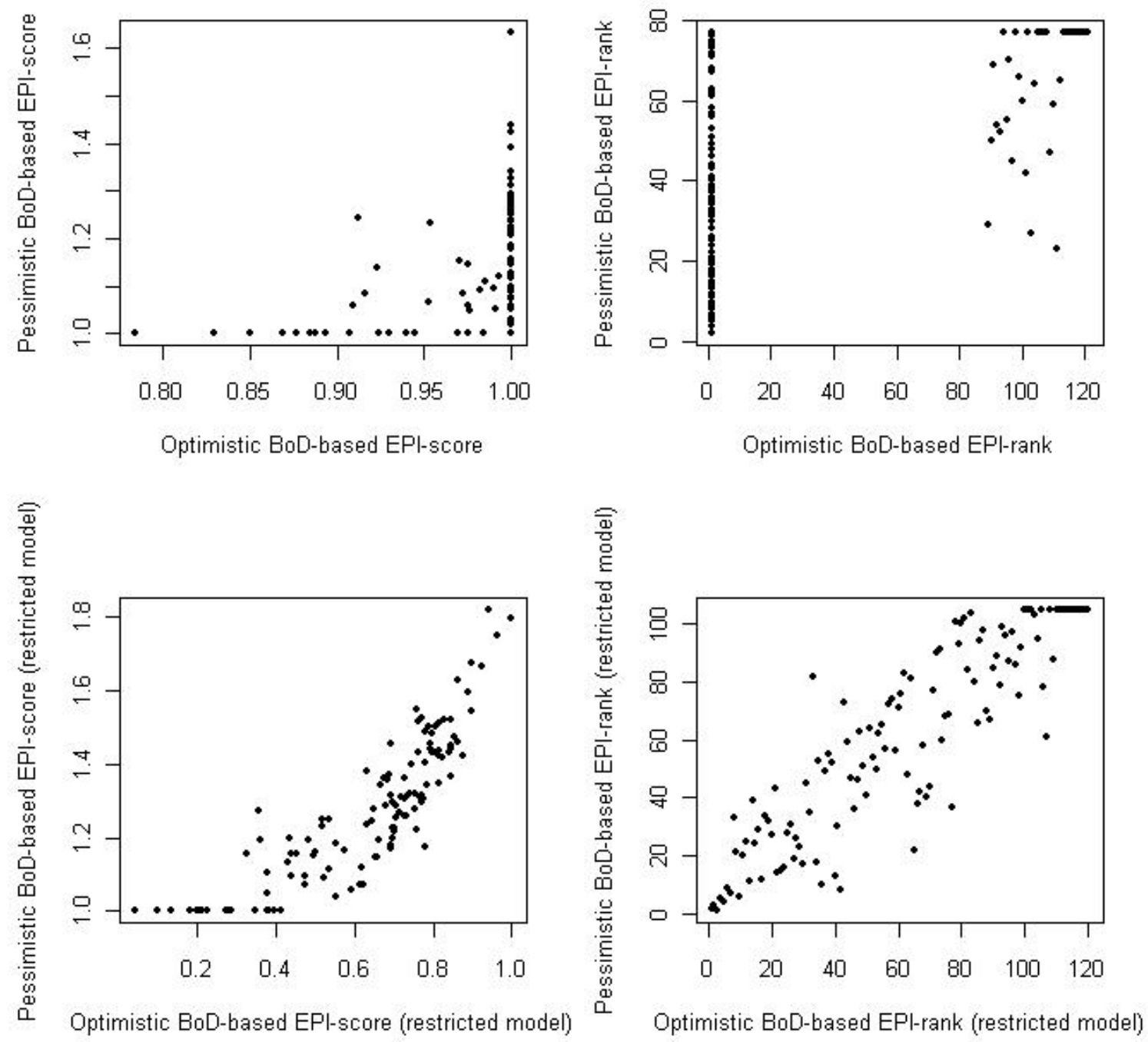
Table 1: Performance scores in the ten policy areas and original EPI scores and rankings

\begin{tabular}{|c|c|c|c|c|c|c|c|c|c|c|c|}
\hline \multirow[b]{2}{*}{ Country } & \multicolumn{3}{|c|}{ Environmental Health } & \multicolumn{7}{|c|}{ Ecosystems Vitality } & \multirow{2}{*}{$\begin{array}{c}\text { Environmental } \\
\text { Performance } \\
\text { Index } \\
\text { (EPI) }\end{array}$} \\
\hline & $\begin{array}{c}\text { Environmental } \\
\text { burden of } \\
\text { disease }\end{array}$ & $\begin{array}{c}\text { Water } \\
\text { resources } \\
\text { for human } \\
\text { health }\end{array}$ & $\begin{array}{c}\text { Air quality } \\
\text { for human } \\
\text { health }\end{array}$ & $\begin{array}{l}\text { Air quality } \\
\text { for } \\
\text { ecosystems }\end{array}$ & $\begin{array}{l}\text { Water } \\
\text { resources } \\
\text { for } \\
\text { ecosystems }\end{array}$ & $\begin{array}{l}\text { Biodiversity } \\
\text { and habitat }\end{array}$ & Forestry & Fisheries & Agriculture & $\begin{array}{l}\text { Climate } \\
\text { change }\end{array}$ & \\
\hline Finland & 82.81 (17) & $97.37(3)$ & $100.00(\mathbf{1})$ & $55.29(\mathbf{2 8})$ & 91.70 (13) & $68.64(42)$ & $100.00(\mathbf{1})$ & $69.49(77)$ & $88.98(\mathbf{2 6})$ & $46.30(\mathbf{8 4})$ & $74.74(10)$ \\
\hline Brazil & $58.50(\mathbf{7 4})$ & 90.18 (34) & $79.33(\mathbf{6 8})$ & $39.31(\mathbf{9 2})$ & $85.63(21)$ & $61.31(\mathbf{5 8})$ & $82.42(96)$ & $89.71(\mathbf{2 8})$ & $90.73(\mathbf{2 2})$ & $46.44(\mathbf{8 3})$ & $63.41(52)$ \\
\hline Canada & $86.86(6)$ & $97.37(3)$ & $100.00(\mathbf{1})$ & 25.27 (116) & $90.72(\mathbf{1 5})$ & $61.91(\mathbf{5 6})$ & $100.00(\mathbf{1})$ & 33.77 (118) & $89.53(\mathbf{2 4})$ & 37.34 (106) & $66.44(38)$ \\
\hline Guinea & $16.40(\mathbf{1 1 4})$ & 16.89 (116) & 28.68 (109) & $49.25(\mathbf{5 1})$ & $72.77(\mathbf{6 2})$ & $46.31(\mathbf{7 8})$ & 86.98 (92) & $71.70(\mathbf{7 4})$ & 77.27 (57) & $69.73(\mathbf{2 4})$ & 44.37 (109) \\
\hline Costa Rica & 77.54 (29) & $77.62(\mathbf{5 4})$ & $96.03(\mathbf{3 6})$ & $59.94(\mathbf{1 6})$ & $73.86(\mathbf{5 4})$ & $73.40(34)$ & $100.00(\mathbf{1})$ & $99.12(2)$ & 90.91 (19) & $78.55(5)$ & $86.40(2)$ \\
\hline Mexico & $73.01(35)$ & $75.46(\mathbf{5 9})$ & $85.03(\mathbf{5 9 )}$ & 40.18 (88) & $59.95(\mathbf{9 2})$ & $51.10(\mathbf{7 2})$ & $87.56(\mathbf{8 8})$ & 89.61 (29) & $80.35(\mathbf{5 4})$ & $56.42(\mathbf{5 4})$ & $67.34(35)$ \\
\hline Indonesia & $45.36(\mathbf{8 8})$ & 31.81 (105) & $55.82(\mathbf{9 2})$ & $41.56(\mathbf{8 1})$ & $79.91(\mathbf{3 0})$ & $63.19(\mathbf{5 1})$ & 18.90 (119) & 70.41 (75) & 86.70 (35) & $49.24(77)$ & $44.61(108)$ \\
\hline UAE & 89.10 (3) & 48.63 (87) & 98.32 (32) & 34.00 (111) & 5.27 (119) & 1.17 (118) & $100.00(\mathbf{1})$ & $50.00(\mathbf{1 0 1})$ & 39.09 (114) & 20.58 (119) & $40.67(116)$ \\
\hline
\end{tabular}


Table 2a: Absolute contributions to the EPI index of core policy areas (unrestricted optimistic BoD-model)

\begin{tabular}{|c|c|c|c|c|c|c|c|c|c|c|c|}
\hline \multirow[b]{2}{*}{ Country } & \multicolumn{3}{|c|}{ Environmental Health } & \multicolumn{7}{|c|}{ Ecosystems Vitality } & \multirow{2}{*}{$\begin{array}{c}\text { EPI } \\
\text { by } \\
\text { optimistic } \\
\text { BoD }\end{array}$} \\
\hline & $\begin{array}{c}\text { Environmental } \\
\text { burden of } \\
\text { disease }\end{array}$ & $\begin{array}{c}\text { Water } \\
\text { resources } \\
\text { for human } \\
\text { health }\end{array}$ & $\begin{array}{l}\text { Air quality } \\
\text { for human } \\
\text { health }\end{array}$ & $\begin{array}{l}\text { Air quality } \\
\text { for } \\
\text { ecosystems }\end{array}$ & $\begin{array}{c}\text { Water } \\
\text { resources } \\
\text { for } \\
\text { ecosystems }\end{array}$ & $\begin{array}{l}\text { Biodiversity } \\
\text { and habitat }\end{array}$ & Forestry & Fisheries & Agriculture & $\begin{array}{l}\text { Climate } \\
\text { change }\end{array}$ & \\
\hline Finland & 0.0000 & 0.0000 & 1.0000 & 0.0000 & 0.0000 & 0.0000 & 0.0000 & 0.0000 & 0.0000 & 0.0000 & 1.0000 \\
\hline Brazil & 0.0000 & 0.1326 & 0.0000 & 0.0000 & 0.2809 & 0.0458 & 0.0000 & 0.4901 & 0.0102 & 0.0160 & 0.9755 \\
\hline Canada & 0.7013 & 0.1594 & 0.0000 & 0.0000 & 0.0000 & 0.0000 & 0.0000 & 0.0000 & 0.1393 & 0.0000 & 1.0000 \\
\hline Guinea & 0.0000 & 0.0000 & 0.0000 & 0.0806 & 0.1805 & 0.0000 & 0.0000 & 0.0000 & 0.2522 & 0.3747 & 0.8879 \\
\hline Costa Rica & 0.5347 & 0.0000 & 0.0000 & 0.0000 & 0.0000 & 0.0000 & 0.0000 & 0.3458 & 0.0000 & 0.1191 & 1.0000 \\
\hline Mexico & 0.3321 & 0.0262 & 0.0000 & 0.0000 & 0.0000 & 0.0000 & 0.0000 & 0.5267 & 0.0000 & 0.0272 & 0.9121 \\
\hline Indonesia & 0.0000 & 0.0000 & 0.0000 & 0.0000 & 0.3396 & 0.2131 & 0.0000 & 0.0000 & 0.3028 & 0.0285 & 0.8840 \\
\hline UAE & 0.0000 & 0.0000 & 0.0000 & 0.0000 & 0.0000 & 0.0000 & 1.0000 & 0.0000 & 0.0000 & 0.0000 & 1.0000 \\
\hline
\end{tabular}


Table 2b: Absolute contributions to the EPI index of core policy areas (unrestricted pessimistic BoD-model)

\begin{tabular}{|c|c|c|c|c|c|c|c|c|c|c|c|}
\hline \multirow[b]{2}{*}{ Country } & \multicolumn{3}{|c|}{ Environmental Health } & \multicolumn{7}{|c|}{ Ecosystems Vitality } & \multirow{2}{*}{$\begin{array}{c}\text { EPI } \\
\text { by } \\
\text { pessimistic } \\
\text { BoD }\end{array}$} \\
\hline & $\begin{array}{c}\text { Environmental } \\
\text { burden of } \\
\text { disease }\end{array}$ & $\begin{array}{c}\text { Water } \\
\text { resources } \\
\text { for human } \\
\text { health }\end{array}$ & $\begin{array}{l}\text { Air quality } \\
\text { for human } \\
\text { health }\end{array}$ & $\begin{array}{l}\text { Air quality } \\
\text { for } \\
\text { ecosystems }\end{array}$ & $\begin{array}{c}\text { Water } \\
\text { resources } \\
\text { for } \\
\text { ecosystems }\end{array}$ & $\begin{array}{l}\text { Biodiversity } \\
\text { and habitat }\end{array}$ & Forestry & Fisheries & Agriculture & $\begin{array}{l}\text { Climate } \\
\text { change }\end{array}$ & \\
\hline Finland & 0.3932 & 0.0000 & 0.0000 & 0.1522 & 0.0000 & 0.0000 & 0.1527 & 0.2115 & 0.0000 & 0.4016 & 1.3111 \\
\hline Brazil & 0.0118 & 0.0000 & 0.3466 & 0.3004 & 0.0000 & 0.0033 & 0.1025 & 0.0000 & 0.0000 & 0.3796 & 1.1442 \\
\hline Canada & 0.3593 & 0.0000 & 0.0164 & 0.1177 & 0.0000 & 0.0000 & 0.1366 & 0.1252 & 0.0000 & 0.2447 & 1.0000 \\
\hline Guinea & 0.1045 & 0.0146 & 0.0135 & 0.1585 & 0.0434 & 0.0781 & 0.0035 & 0.1220 & 0.0191 & 0.4430 & 1.0000 \\
\hline Costa Rica & 0.3122 & 0.0214 & 0.0000 & 0.3503 & 0.0000 & 0.0000 & 0.1329 & 0.3389 & 0.0000 & 0.4784 & 1.6340 \\
\hline Mexico & 0.0652 & 0.0000 & 0.2294 & 0.4102 & 0.0421 & 0.0000 & 0.1589 & 0.0000 & 0.0000 & 0.3371 & 1.2429 \\
\hline Indonesia & 0.0783 & 0.0000 & 0.1043 & 0.1539 & 0.0000 & 0.0000 & 0.0516 & 0.0000 & 0.2293 & 0.3825 & 1.0000 \\
\hline UAE & 0.1539 & 0.0000 & 0.1837 & 0.1259 & 0.0000 & 0.0000 & 0.2733 & 0.0000 & 0.1034 & 0.1599 & 1.0000 \\
\hline
\end{tabular}


Table 3a: Absolute contributions to the EPI index of core policy areas (restricted optimistic BoD-model)

\begin{tabular}{|c|c|c|c|c|c|c|c|c|c|c|c|}
\hline \multirow[b]{2}{*}{ Country } & \multicolumn{3}{|c|}{ Environmental Health } & \multicolumn{7}{|c|}{ Ecosystems Vitality } & \multirow{2}{*}{$\begin{array}{c}\text { EPI } \\
\text { by } \\
\text { optimistic } \\
\text { BoD }\end{array}$} \\
\hline & $\begin{array}{c}\text { Environmental } \\
\text { burden of } \\
\text { disease }\end{array}$ & $\begin{array}{c}\text { Water } \\
\text { resources } \\
\text { for human } \\
\text { health }\end{array}$ & $\begin{array}{c}\text { Air quality } \\
\text { for human } \\
\text { health }\end{array}$ & $\begin{array}{l}\text { Air quality } \\
\text { for } \\
\text { ecosystems }\end{array}$ & $\begin{array}{c}\text { Water } \\
\text { resources } \\
\text { for } \\
\text { ecosystems }\end{array}$ & $\begin{array}{l}\text { Biodiversity } \\
\text { and habitat }\end{array}$ & Forestry & Fisheries & Agriculture & $\begin{array}{l}\text { Climate } \\
\text { change }\end{array}$ & \\
\hline Finland & 0.1605 & 0.1337 & 0.1337 & 0.0449 & 0.0428 & 0.0449 & 0.0449 & 0.0449 & 0.0449 & 0.1605 & 0.8560 \\
\hline Brazil & 0.141 & 0.1175 & 0.1156 & 0.0395 & 0.0395 & 0.0395 & 0.0395 & 0.0395 & 0.0395 & 0.141 & 0.7519 \\
\hline Canada & 0.204 & 0.1185 & 0.1185 & 0.0239 & 0.0239 & 0.0239 & 0.0398 & 0.0239 & 0.0398 & 0.1422 & 0.7585 \\
\hline Guinea & 0.0706 & 0.0353 & 0.0353 & 0.0198 & 0.0198 & 0.0188 & 0.0198 & 0.0198 & 0.0198 & 0.1176 & 0.3765 \\
\hline Costa Rica & 0.177 & 0.0885 & 0.1475 & 0.0495 & 0.0297 & 0.0495 & 0.0495 & 0.0495 & 0.0495 & 0.2534 & 0.9438 \\
\hline Mexico & 0.2312 & 0.0749 & 0.1248 & 0.0419 & 0.0252 & 0.0252 & 0.0419 & 0.0419 & 0.0419 & 0.1497 & 0.7985 \\
\hline Indonesia & 0.1007 & 0.0503 & 0.0839 & 0.0282 & 0.0282 & 0.0282 & 0.0169 & 0.0282 & 0.0282 & 0.1442 & 0.5370 \\
\hline UAE & 0.0705 & 0.0212 & 0.0353 & 0.0114 & 0.0071 & 0.0071 & 0.0118 & 0.0118 & 0.0071 & 0.0423 & 0.2256 \\
\hline
\end{tabular}


Table 3b: Percentage contributions to the EPI index of core policy areas (restricted optimistic BoD-model)

\begin{tabular}{|c|c|c|c|c|c|c|c|c|c|c|c|}
\hline \multirow[b]{2}{*}{ Country } & \multicolumn{3}{|c|}{ Environmental Health } & \multicolumn{7}{|c|}{ Ecosystems Vitality } & \multirow[b]{2}{*}{$\begin{array}{c}\text { EPI } \\
\text { by } \\
\text { optimistic } \\
\text { BoD }\end{array}$} \\
\hline & $\begin{array}{c}\text { Environmental } \\
\text { burden of } \\
\text { disease }\end{array}$ & $\begin{array}{c}\text { Water } \\
\text { resources } \\
\text { for human } \\
\text { health }\end{array}$ & $\begin{array}{c}\text { Air quality } \\
\text { for human } \\
\text { health }\end{array}$ & $\begin{array}{l}\text { Air quality } \\
\text { for } \\
\text { ecosystems }\end{array}$ & $\begin{array}{c}\text { Water } \\
\text { resources } \\
\text { for } \\
\text { ecosystems }\end{array}$ & $\begin{array}{l}\text { Biodiversity } \\
\text { and habitat }\end{array}$ & Forestry & Fisheries & Agriculture & $\begin{array}{l}\text { Climate } \\
\text { change }\end{array}$ & \\
\hline Finland & $0.1875^{\mathrm{L}}$ & $0.1563^{\mathrm{H}}$ & $0.1562^{\mathrm{H}}$ & $0.0525^{\mathrm{H}}$ & 0.05 & $0.0525^{\mathrm{H}}$ & $0.0525^{\mathrm{H}}$ & $0.0525^{\mathrm{H}}$ & $0.0525^{\mathrm{H}}$ & $0.1875^{\mathrm{L}}$ & 0.8560 \\
\hline Brazil & $0.1875^{\mathrm{L}}$ & $0.1563^{\mathrm{H}}$ & 0.1537 & $0.0525^{\mathrm{H}}$ & $0.0525^{\mathrm{H}}$ & $0.0525^{\mathrm{H}}$ & $0.0525^{\mathrm{H}}$ & $0.0525^{\mathrm{H}}$ & $0.0525^{\mathrm{H}}$ & $0.1875^{\mathrm{L}}$ & 0.7519 \\
\hline Canada & 0.269 & $0.1563^{\mathrm{H}}$ & $0.1563^{\mathrm{H}}$ & $0.0315^{\mathrm{L}}$ & $0.0315^{\mathrm{L}}$ & $0.0315^{\mathrm{L}}$ & $0.0525^{\mathrm{H}}$ & $0.0315^{\mathrm{L}}$ & $0.0525^{\mathrm{H}}$ & $0.1875^{\mathrm{L}}$ & 0.7585 \\
\hline Guinea & $0.1875^{\mathrm{L}}$ & $0.0938^{\mathrm{L}}$ & $0.0938^{\mathrm{L}}$ & $0.0525^{\mathrm{H}}$ & $0.0525^{\mathrm{H}}$ & 0.05 & $0.0525^{\mathrm{H}}$ & $0.0525^{\mathrm{H}}$ & $0.0525^{\mathrm{H}}$ & $0.3125^{\mathrm{H}}$ & 0.3765 \\
\hline Costa Rica & $0.1875^{\mathrm{L}}$ & $0.0937^{\mathrm{L}}$ & $0.1562^{\mathrm{H}}$ & $0.0525^{\mathrm{H}}$ & $0.0315^{\mathrm{L}}$ & $0.0525^{\mathrm{H}}$ & $0.0525^{\mathrm{H}}$ & $0.0525^{\mathrm{H}}$ & $0.0525^{\mathrm{H}}$ & 0.2685 & 0.9438 \\
\hline Mexico & 0.2895 & $0.0937^{\mathrm{L}}$ & $0.1562^{\mathrm{H}}$ & $0.0525^{\mathrm{H}}$ & $0.0315^{\mathrm{L}}$ & $0.0315^{\mathrm{L}}$ & $0.0525^{\mathrm{H}}$ & $0.0525^{\mathrm{H}}$ & $0.0525^{\mathrm{H}}$ & $0.1875^{\mathrm{L}}$ & 0.7985 \\
\hline Indonesia & $0.1875^{\mathrm{L}}$ & $0.0937^{\mathrm{L}}$ & $0.1562^{\mathrm{H}}$ & $0.0525^{\mathrm{H}}$ & $0.0525^{\mathrm{H}}$ & $0.0525^{\mathrm{H}}$ & $0.0315^{\mathrm{L}}$ & $0.0525^{\mathrm{H}}$ & $0.0525^{\mathrm{H}}$ & 0.2685 & 0.5370 \\
\hline UAE & $0.3125^{\mathrm{H}}$ & $0.0937^{\mathrm{L}}$ & $0.1563^{\mathrm{H}}$ & $0.0505^{\mathrm{H}}$ & $0.0315^{\mathrm{L}}$ & $0.0315^{\mathrm{L}}$ & $0.0525^{\mathrm{H}}$ & $0.0525^{\mathrm{H}}$ & $0.0315^{\mathrm{L}}$ & $0.1875^{\mathrm{L}}$ & 0.2256 \\
\hline
\end{tabular}

$\mathrm{L}_{\mathrm{L}}$ the weight restriction attains the lower bound; ${ }^{\mathrm{H}}$ : the weight restriction attains the upper bound 